\title{
Publisher Correction: Discovery of coding regions in the human genome by integrated proteogenomics analysis workflow
}

\author{
Yafeng Zhu', Lukas M. Orre', Henrik J. Johansson (1) ${ }^{1}$, Mikael Huss ${ }^{2}$, Jorrit Boekel ${ }^{3}$, Mattias Vesterlund (1D ${ }^{1}$, \\ Alejandro Fernandez-Woodbridge ${ }^{1}$, Rui M.M. Branca ${ }^{1} \&$ Janne Lehtiö ${ }^{1}$
}

Correction to: Nature Communications https://doi.org/10.1038/s41467-018-03311-y, published online 02 March 2018

In the original version of this Article, extraneous text not belonging to the Article was accidentally appended to the "Results" section. This error has now been corrected in both the PDF and HTML versions of the Article.

Published online: 08 May 2018

\begin{abstract}
(c) (i) Open Access This article is licensed under a Creative Commons Attribution 4.0 International License, which permits use, sharing, adaptation, distribution and reproduction in any medium or format, as long as you give appropriate credit to the original author(s) and the source, provide a link to the Creative Commons license, and indicate if changes were made. The images or other third party material in this article are included in the article's Creative Commons license, unless indicated otherwise in a credit line to the material. If material is not included in the article's Creative Commons license and your intended use is not permitted by statutory regulation or exceeds the permitted use, you will need to obtain permission directly from the copyright holder. To view a copy of this license, visit http://creativecommons.org/licenses/by/4.0/.
\end{abstract}

(C) The Author(s) 2018

\footnotetext{
${ }^{1}$ Department of Oncology-Pathology, Science for Life Laboratory, Karolinska Institutet, Tomtebodavägen 23A, 17165 Stockholm, Sweden. ${ }^{2}$ Department of Biochemistry and Biophysics, The Arrhenius Laboratories for Natural Sciences, Science for Life Laboratory, Stockholm University, Tomtebodavägen $23 \mathrm{~A}, 171$ 65 Stockholm, Sweden. ${ }^{3}$ Department of Oncology-Pathology, NBIS (National Bioinformatics Infrastructure Sweden), Science for Life Laboratory, Karolinska Institutet, Tomtebodavägen 23A, 17165 Stockholm, Sweden. These authors contributed equally: Rui M. M. Branca, Janne Lehtiö. Correspondence and requests for materials should be addressed to R.M.M.B. (email: rui.mamede-branca@ki.se) or to J.Lö. (email: janne.lehtio@ki.se)
} 